\title{
Detection of Paralytic Shellfish Toxins in Mussels and Oysters Using the Qualitative Neogen Lateral-Flow Immunoassay: An Interlaboratory Study
}

\author{
JuAn José Dorantes-Aranda \\ University of Tasmania, Institute for Marine and Antarctic Studies, Private Bag 129, Hobart, TAS 7001, Australia \\ JESSICA Y.C. TAN \\ South Australian Research and Development Institute, 2b Hartley Grv., Urrbrae, SA 5064, Australia \\ GustaAf M. HallegraefF \\ University of Tasmania, Institute for Marine and Antarctic Studies, Private Bag 129, Hobart, TAS 7001, Australia \\ Katrina CAMPBElL \\ Queen's University Belfast, School of Biological Sciences, Institute for Global Food Security, David Keir Building, Stranmillis Rd, \\ Belfast, BT9 5AG, United Kingdom \\ SARAh C. Ugalde \\ University of Tasmania, Institute for Marine and Antarctic Studies, Private Bag 129, Hobart, TAS 7001, Australia \\ D. Tim HaRwOOD
}

Cawthron Institute, 98 Halifax St, Nelson 7010, New Zealand

JiLL K. BARTLETT

University of Canberra, Institute for Applied Ecology, ACT 2617, Australia

Mònica CAMPàs

IRTA, Carretera de Poble Nou, km 5.5, 43540 Sant Carles de la Ràpita, Spain

Steven Crooks

Agri-Food and Biosciences Institute, Veterinary Sciences Division, Belfast, United Kingdom

ArJen Gerssen

Wageningen University and Research, RIKILT, Wageningen, The Netherlands

KeITH HARRISON

Centre for Environment Fisheries and Aquaculture Science, Barrack Rd, The Nothe, Weymouth, Dorset DT4 8UB, United Kingdom Anne-Catherine Huet

CER Groupe, Health Department, Rue du Point du Jour 8, 6900 Marloie, Belgium

Timothy B. JoRDAN

Analytical Services Tasmania, 18 St Johns Ave, New Town, Hobart, TAS 7008, Australia

MARTINA KoEberL

National Measurement Institute, 1/153 Bertie St, Port Melbourne, VIC 3207, Australia

Tim Monaghan

Cameron of Tasmania, 145-149 Arthur Hwy, Dunalley, TAS 7177, Australia

SAM MurRay

Cawthron Institute, 98 Halifax St, Nelson 7010, New Zealand

RAMA NimMagadDA

Advanced Analytical Australia Pty Ltd, 11 Julius Ave, North Ryde, NSW 2113, Australia

CORINNe OOMS

Spring Bay Seafoods, 488 Freestone Point Rd, Triabunna, TAS 7190, Australia

RAE K. QUiNLAN

University of Tasmania, Institute for Marine and Antarctic Studies, Private Bag 129, Hobart, TAS 7001, Australia

FENG SHI

Advanced Analytical Australia Pty Ltd, 11 Julius Ave, North Ryde, NSW 2113, Australia

ANDREW D. TURner

Centre for Environment Fisheries and Aquaculture Science, Barrack Rd, The Nothe, Weymouth, Dorset DT4 8UB, United Kingdom BetSY JeAN YAKES

U.S. Food and Drug Administration, Center for Food Safety and Applied Nutrition, Office of Regulatory Science, College Park, MD Alison R. Turnbull

South Australian Research and Development Institute, 2b Hartley Grv., Urrbrae, SA 5064, Australia

\footnotetext{
Received June 1, 2017. Accepted by AP July 23, 2017.

Corresponding author's e-mail: juanjodorantes@gmail.com

This work was funded by SafeFish, the Fisheries Research and

Development Corporation, and the Australian Department of Agriculture and Water Resources.

DOI: https://doi.org/10.5740/jaoacint.17-0221
}

Paralytic shellfish toxins (PSTs) in bivalve molluscs
represent a public health risk and are controlled via
compliance with a regulatory limit of $0.8 \mathrm{mg}$
saxitoxin (STX) $2 \mathrm{HCl}$ equivalents per kilogram of 
shellfish meat (eq/kg). Shellfish industries would benefit from the use of rapid immunological screening tests for PSTs to be used for regulation, but to date none have been fully validated. An interlaboratory study involving 16 laboratories was performed to determine the suitability of the Neogen test to detect PSTs in mussels and oysters. Participants performed the standard protocol recommended by the manufacturer and a modified protocol with a conversion step to improve detection of gonyautoxin 1\&4. The statistical analysis showed that the protocols had good homogeneity across all laboratories, with satisfactory repeatability, laboratory, and reproducibility variation near the regulatory level. The mean probability of detection (POD) at $0.8 \mathrm{mg}$ $S T X \cdot 2 \mathrm{HCl}$ eq $/ \mathrm{kg}$ using the standard protocol in mussels and oysters was 0.966 and 0.997 , respectively, and 0.968 and 0.966 using the modified protocol. The estimated LOD in mussels was $0.316 \mathrm{mg} \mathrm{STX} \cdot 2 \mathrm{HCl}$ eq $/ \mathrm{kg}$ with the standard and $0.682 \mathrm{mg} \mathrm{STX} \cdot 2 \mathrm{HCl}$ eq/ $\mathrm{kg}$ with the modified protocol, and 0.710 and $0.734 \mathrm{mg} \mathrm{STX} \cdot 2 \mathrm{HCl} \mathrm{eq} / \mathrm{kg}$ for oysters, respectively. The Neogen test may be acceptable for regulatory purposes for oysters in accordance with European Commission directives in which the standard protocol provides, at the regulatory level, a probability of a negative response of 0.033 on $95 \%$ of occasions. Its use for mussels is less consistent at the regulatory level due to the wide prediction interval around the POD.

$\mathrm{S}$ hellfish industries are severely impacted worldwide by the toxic dinoflagellates Gymnodinium catenatum, Pyrodinium bahamense, and species of the genus Alexandrium (1). These algae produce potent neurotoxins, comprising saxitoxin (STX) and its congeners, which are naturally bioaccumulated by shellfish and can cause paralytic shellfish poisonings in humans that consume contaminated shellfish. Blooms created by these dinoflagellates are increasing in recurrence and distribution (2) and cause shellfish farm closures and product recalls. Collecting wild shellfish during toxic blooms in areas where poor monitoring occurs, or no warning signage is present, has resulted in human poisonings and hospitalizations and, in extreme cases, in fatalities (3).

In many countries, shellfish industries are required to undertake biotoxin monitoring to ensure their product is both safe to eat and able to enter domestic and international markets. For regulation purposes, the recommended maximum allowable level of paralytic shellfish toxins (PSTs) is $0.8 \mathrm{mg}$ $\mathrm{STX} \cdot 2 \mathrm{HCl}$ equivalents per kilogram of shellfish meat or $0.8 \mathrm{mg} \mathrm{STX} \cdot 2 \mathrm{HCl} \mathrm{eq} / \mathrm{kg} \mathrm{(4)}$; however, this may vary in some countries. For instance, the regulatory level adopted in the Philippines is $0.6 \mathrm{mg} \mathrm{STX} \mathrm{eq/kg} \mathrm{(5).} \mathrm{In} \mathrm{Australia,} \mathrm{according}$ to the Australia New Zealand Food and Standards Code, the regulatory level is $0.8 \mathrm{mg} \mathrm{STX} \mathrm{eq/} / \mathrm{kg}$ (6), but not as $2 \mathrm{HCl}$ salt, which may vary compared with total PST in $\mathrm{mg}$ $\mathrm{STX} \cdot 2 \mathrm{HCl}$ eq $/ \mathrm{kg}$. The mouse bioassay (MBA; AOAC 959.08) was the official method for the determination of PST for many years, but in 2015 the Codex standard was revised to include chemical methods as well as biological and functional methods as alternative regulatory tools (7). The United Kingdom, Ireland, Australia, and New Zealand adopted a precolumn oxidation (Pre-COX) LC method with fluorescence detection (LC-FLD; AOAC 2005.06 or the Lawrence method; 8) as the primary regulatory method. Further analytical methods have been validated and accepted by AOAC INTERNATIONAL for PST testing in shellfish, including a postcolumn oxidation (PCOX) LC-FLD method (AOAC 2011.02; 9), and a receptorbinding assay (RBA; AOAC 2011.27; 10), with improved methods currently undergoing validation [i.e., hydrophilic interaction LC (HILIC)-tandem MS (MS/MS); 11]. The U.S. Food and Drug Administration (FDA), through the National Shellfish Sanitation Program (NSSP), has recently approved the RBA (for mussels) and PCOX methods as alternatives for PST determination (12). Canada has recently moved away from the MBA and has adopted the PCOX method as the primary method for PST testing (13). However, some countries are still using the MBA as the reference method, and despite the disadvantages of being labor-intensive, having high variability, and societal concerns about animal usage, these countries do not adopt analytical tests due to the instrument expenses involved, the need for specialists to analyze the samples, and the routine use of expensive certified reference materials (1).

Due to the high cost of the biological (MBA) and analytical (e.g., LC-FLD) tests, recent studies have focused on the search for inexpensive and reliable rapid tests that could be used for screening purposes (14-18) in which negative test results would no longer require further expensive analysis for harvesting and product release. A review of available field methods for the detection of marine toxins in shellfish was recently published (19), which not only included PSTs, but also amnesic and diarrhetic shellfish toxins. The first rapid test for PSTs, the Scotia Rapid Test (SRT; formerly MIST Alert and Jellett) was introduced in the early 2000s $(20,21)$. This is a qualitative lateralflow immunoassay (LFIA) that returns a positive or negative result. Quantitative ELISA rapid test kits have also been produced and are commercially available, including Abraxis, Europroxima, Beacon, Bioo Scientific, and R-Biopharm. Rapid tests are developed to target mainly STX, with varying crossreactivity for other PST analogs, with the antibody used showing a very low reactivity for gonyautoxin $1 \& 4$ (GTX1\&4), which is commonly found in contaminated shellfish from Australia and the United Kingdom $(16,17,22)$. GTX1\&4 is a highly potent PST analog, and when present at high levels in a contaminated sample, the result returned by the kits could be underestimated due to the low reactivity of the antibody for this analog. Thus, not all rapid test kits are suitable for all regions due to their limited crossreactivity for some toxin analogs. The SRT was calibrated using a mixture of PSTs and possesses a low reactivity for GTX1\&4. An extra conversion step for shellfish samples that are suspected to contain GTX1\&4 can be performed (23), which, according to the manufacturer, increases the cross-reactivity from 1.8 to $26 \%$, but also increases the time of analysis. The comparative performance of rapid test kits has demonstrated their limitation for analogs different from STX, as well as for highly contaminated samples due to the limited working range of their calibration curves (i.e., quantitative ELISA kits; 16, 17). Moreover, the qualitative SRT has been shown to return a large number of false-noncompliant results (i.e., positive results for samples that contained $<0.8 \mathrm{mg}$ $\mathrm{STX} \cdot 2 \mathrm{HCl}$ eq $/ \mathrm{kg} ; 14,15,17,23,24)$.

Geographical areas where shellfish are contaminated mainly with STXs have benefited from the use of rapid test kits due to their specific selectivity for this particular analog. Such is the 
case with Georges Bank in the United States in which the use of the SRT and a modified version of the Abraxis ELISA kit led to their limited-use approval by the NSSP for regulatory purposes. The SRT was approved in 2004 to be used specifically to (1) determine when to perform an MBA in a previously closed area, (2) maintain an area in the open status, and (3) instigate a precautionary closure. The Abraxis Shipboard ELISA was approved in 2011, offering a few advantages over the SRT because it is a quantitative tool and does not return many false-noncompliant results $(12,15)$. The more recent LFIA Neogen kit (25) has proven to offer important advantages over other rapid test kits, such as time of analysis, ease of use, suitability for field use, low cost, and use of a reader that allows an objective assessment of the test result. It is a qualitative tool that returns less false-noncompliant results than the SRT, although the recent work by Harrison et al. (16) and DorantesAranda et al. (17) found a small number of false-compliant results (i.e., negative results for samples that contained $\geq 0.8 \mathrm{mg}$ $\mathrm{STX} \cdot 2 \mathrm{HCl} \mathrm{eq} / \mathrm{kg}$ ). Dorantes-Aranda et al. (17) successfully introduced a conversion step that eliminated the falsecompliant results, and thus recommended the Neogen LFIA as an appropriate rapid tool for shellfish contaminated with GTX1\&4, as is the case for Tasmanian (Australian) shellfish. Additionally, the single-laboratory validation (SLV) of this rapid kit, which followed AOAC guidelines for validation of qualitative binary chemistry tests, fulfilled the selectivity for PSTs and returned a satisfactory matrix and probability of detection (POD) of 1.0 at the regulatory limit for oysters and mussels (26).

In this study, we present the outcomes of an interlaboratory study using the Neogen kit to detect PSTs in mussels (Mytilus galloprovincialis) and oysters (Crassostrea gigas) using AOAC procedures for the validation of binary qualitative tests (27). The methodology included both the standard protocol recommended by the manufacturer and a modified protocol proposed by Dorantes-Aranda et al. (17), which involves a conversion step to increase the cross-reactivity of GTX1\&4 and gonyautoxin $2 \& 3$ (GTX) to the antibody used in the test kits. If the results of the study prove satisfactory (i.e., positive responses at the regulatory limit and above, with a false-compliant error of $<5 \%$ ), the test kit will provide international shellfish industries and potentially regulators with a rapid tool to detect PSTs in mussels and oysters, creating significant savings in costs and time when negative test results will no longer require further testing with more expensive and time-consuming analytical methods.

\section{METHODS}

\section{Interlaboratory Study}

The study was structured and performed following AOAC's Guidelines for Validation of Qualitative Binary Chemistry Methods (27). Eighteen laboratories were invited to participate in this study, of which 17 agreed. These laboratories were distributed in eight countries: Australia, Belgium, China, the Netherlands, New Zealand, Spain, the United Kingdom, and the United States. Participants included government regulatory laboratories as well as research institutes and centers, university laboratories, independent/commercial laboratories, and a shellfish hatchery QA laboratory. Some laboratories were experienced with analytical tests, but not with rapid tests; others with both; and others did not have any experience with any type of tests. All laboratories carried out the tests with Neogen rapid kits, and three laboratories from Australia, New Zealand, and the United Kingdom also performed the Pre-COX analytical chemistry method (8) on the samples.

All laboratories were provided with consumables to carry out the rapid Neogen tests, including sample cups, disposable pipets (supplied with kits), L-cysteine to perform the extra conversion step, and a reader to obtain the final positive/negative result.

\section{Preparation of Shellfish Homogenates}

Mediterranean mussel (M. galloprovincialis) and Pacific oyster (C. gigas) homogenates were sourced from the Tasmanian Shellfish Quality Assurance Program (TSQAP) from samples that were part of the routine biotoxin-monitoring program analyzed using the Pre-COX method. PST-free mussels and oysters were collected from areas free of toxins where blooms had not occurred (confirmed with the Pre-COX method). Eight naturally contaminated shellfish homogenates were used for this study, four of each matrix, which were diluted using the PST-free shellfish homogenates to achieve concentration levels targeted at $0,0.2,0.6$, and $0.8 \mathrm{mg} \mathrm{STX} \cdot 2 \mathrm{HCl} \mathrm{eq} / \mathrm{kg}$. PST-contaminated homogenates originated from blooms of Alexandrium tamarense (group 1) that occurred on the east coast of Tasmania during 2012, 2015, and 2016, and from a bloom of G. catenatum in the Derwent River, Tasmania, in 2015. One naturally contaminated sample was spiked with STX standard to ensure there was a sample with a broader toxin profile, and another sample was spiked with GTX1\&4 standard. Both standards were purchased from the National Research Council (NRC)-Canada. Shellfish homogenates were mixed for at least 20 min using an electric blender to achieve sample homogeneity.

Each laboratory received two sets of six replicates of all eight shellfish homogenates (96 samples in total), which were randomly labeled using numbers generated from Random.org (28). The participants tested the samples using one set for (1) the standard protocol by the manufacturer and (2) a modified protocol with an extra conversion step, as per Dorantes-Aranda et al. (17). Each sample tube contained $1.5 \mathrm{~g}$ shellfish homogenate.

\section{Shipment of Material}

(a) Samples.-Samples were separated into two sets per package, corresponding to those to be analyzed with the standard or modified protocol. An extra set of six blind shellfish homogenates was included so that laboratories were able to practice the protocols before testing the experimental samples. Samples that were sent to laboratories outside of Tasmania (i.e., mainland Australia or overseas) were dispatched in dry ice to keep samples frozen, except for those sent to New Zealand, which contained ice packs and were placed in a freezer at each connection point (dry ice is prohibited for import). Each parcel was accompanied by paper work for export and import of samples by the laboratories, including declaration letters and permits. A list of the contents, test protocols, result sheets, and instructions for AccuScan Pro reader setup were also sent with the samples.

(b) AccuScan Pro reader.-The endpoint of the test is analyzing the lateral-flow test strip with the AccuScan Pro reader in the recommended timeframe, which gives a positive or negative result. Readers were sent to all laboratories from the 
Neogen headquarters in the United States; Neogen distributors in destination countries were used, when available, to import and deliver the readers to the laboratories.

(c) Neogen kits.-Neogen test kits were sent to all laboratories from the Neogen European headquarters in Scotland. All laboratories received the same lot number of Neogen kits (Lot No. 9562-20). According to production, one box with kits contained 24 lateral-flow test strips, 24 buffer containers, 24 microwells, 25 extraction bags, and 48 disposable $100 \mu \mathrm{L}$ pipets. Four of these boxes were provided to each laboratory, for a total of 96 tests, plus a mini kit with 6 tests (same lot, No. 9562-20) in case any samples needed to be retested; another mini kit with 6 tests (Lot No. 9562-07) was also provided for laboratories to run practice tests. Marine biotoxin starter kits (Neogen 9563) were also provided to laboratories. Each starter kit contained a microwell holder, roller, and bag clip to perform shellfish toxin extractions.

\section{Protocols for the Neogen Rapid Test}

(a) Standard protocol.-Laboratories were instructed to weigh out $1 \mathrm{~g}( \pm 0.05 \mathrm{~g})$ homogenate in a sample cup, add $30 \mathrm{~mL}( \pm 0.05 \mathrm{~mL})$ distilled or Milli-Q water, and mix vigorously for $30 \mathrm{~s}$. This mix was poured into one side of the extraction bag, sealed with the bag clip, and then mixed for $30 \mathrm{~s}$ using the roller. The filtered solution from the other side of the extraction bag was returned to the sample cup and mixed for another $30 \mathrm{~s} ; 100 \mu \mathrm{L}$ of this extract was transferred into a buffer container and mixed for $30 \mathrm{~s}$. One hundred microliters were transferred into a microwell and a lateral-flow test strip placed in the microwell to incubate for $5 \mathrm{~min}$, after which the strip was read using the AccuScan Pro reader (25).

(b) Modified protocol with conversion step.-This protocol is presented in detail in Dorantes-Aranda et al. (17). Participants were requested to weigh out $1 \mathrm{~g}( \pm 0.05 \mathrm{~g})$ homogenate in a sample cup, add $45.5 \mathrm{~mL}( \pm 0.05 \mathrm{~mL})$ distilled or Milli-Q water, and mix vigorously for $30 \mathrm{~s}$. This suspension was poured into the extraction bag, sealed with the bag clip, and then mixed for $30 \mathrm{~s}$ using the roller. The extract was returned to the sample cup and mixed for another $30 \mathrm{~s} ; 300 \mu \mathrm{L}$ were transferred into a vial containing L-cysteine (final concentration of $2 \mathrm{M}$ ), mixed well for $30 \mathrm{~s}$, and incubated in a water bath at $70^{\circ} \mathrm{C}$ for $30 \mathrm{~min}$. The extract was allowed to cool down for approximately $5 \mathrm{~min}$ in ice, removed and mixed for $30 \mathrm{~s}$, and $100 \mu \mathrm{L}$ transferred into a buffer container and mixed for $30 \mathrm{~s}$. One hundred microliters of the extract diluted in buffer were transferred into a microwell, and a test strip placed in the microwell with the sample, which was incubated for $5 \mathrm{~min}$, after which the strip was read using the AccuScan Pro reader.

\section{LC Analysis}

Three laboratories were asked to analyze the eight shellfish homogenates with the Pre-COX method. Eight extra samples with approximately $6 \mathrm{~g}$ each were provided to the three laboratories for this purpose. These laboratories performed the Pre-COX method with their own minor refinement versions, as described below. All laboratories used PST-certified standards from NRC-Canada for toxin quantification by comparing the samples' peak areas with those of the standards. Analytical results returned by the three laboratories were adjusted to
STX $\cdot 2 \mathrm{HCl}$ eq with total toxicity recalculated using toxicity equivalency factors (TEFs) recommended by the Food and Agriculture Organization of the United Nations (FAO) and the World Health Organization (WHO; 29) to allow for the unification of the data and comparability.

(a) Laboratory A.-PSTs were extracted from $5.0 \pm 0.1 \mathrm{~g}$ shellfish homogenate. A volume of $3 \mathrm{~mL}$ of $1 \%$ acetic acid was added and the mixture mixed on a vortex mixer for $90 \mathrm{~s}$. The samples were placed in a boiling water bath for $5 \mathrm{~min}$ and cooled in running cold water for another 5 min before mixing on the vortex mixer for $90 \mathrm{~s}$ and centrifugation at $3600 \times \mathrm{g}$ for $10 \mathrm{~min}$. The supernatant was recovered, the pellet was resuspended in $3 \mathrm{~mL}$ of $1 \%$ acetic acid, and the solution was mixed on the vortex mixer and centrifuged again. Both supernatants were combined and diluted to a $10 \mathrm{~mL}$ volume with deionized water. Sample extracts were cleaned up using solid-phase extraction (SPE) cartridges (Phenomenex, C18-T). HPLC analysis was performed on an Agilent 1200 HPLC system with FLD (excitation, $340 \mathrm{~nm}$; emission, $395 \mathrm{~nm}$ ). Chromatographic analysis was carried out with a Phenomenex Kinetex column $(150 \times 4.6 \mathrm{~mm}$ id, $5.0 \mu \mathrm{m}$ particle size $)$ in conjunction with a Security Guard (Part No. KJO-4282 and AJO-7597). Mobile phases $\mathrm{A}$ and $\mathrm{B}$ consisted of $0.1 \mathrm{M}$ aqueous ammonium formate and $0.1 \mathrm{M}$ ammonium formate with $5 \%$ acetonitrile, respectively; the $\mathrm{pH}$ was adjusted to $6.0 \pm 0.1$ with $0.1 \mathrm{M}$ acetic acid, and a flow rate of $2 \mathrm{~mL} / \mathrm{min}$ was used. The solvent gradient was $100 \%$ solvent $\mathrm{A}$, increasing to $80 \%$ solvent $\mathrm{B}$ at $4 \mathrm{~min}$ and maintained through to $5.5 \mathrm{~min}$, and then returning to $100 \%$ solvent $\mathrm{A}$ at $5.51 \mathrm{~min}$, with column re-equilibration through to $7 \mathrm{~min}$. Total toxicity was reported as STX $\cdot 2 \mathrm{HCl}$ eq using the TEFs recommended by the European Food Safety Authority (EFSA; 30).

(b) Laboratory B.-PSTs were extracted from $5.0 \pm 0.1 \mathrm{~g}$ shellfish homogenate. A volume of $3 \mathrm{~mL}$ of $1 \%$ acetic acid was added and the mixture mixed on the vortex mixer for $90 \mathrm{~s}$. The samples were placed in a boiling water bath for $5 \mathrm{~min}$ and cooled in running cold water for another 5 min before mixing on the vortex mixer for $90 \mathrm{~s}$ and centrifugation at $3200 \times \mathrm{g}$ for $10 \mathrm{~min}$. The supernatant was recovered, the pellet was resuspended in $3 \mathrm{~mL}$ of $1 \%$ acetic acid, and the solution mixed on the vortex mixer and centrifuged again. Both supernatants were combined and diluted to a $10 \mathrm{~mL}$ volume with deionized water. Sample extracts were cleaned up using Phenomenex polymeric Strata-X SPE cartridges. The ultra-performance LC (UPLC) method was carried out on a Waters Acquity instrument coupled with FLD (excitation, $340 \mathrm{~nm}$; emission, $395 \mathrm{~nm}$ ). Chromatographic separation was carried out with a Phenomenex Kinetex C18 reversed-phase column $(100 \times 2.1 \mathrm{~mm}$ id, $1.7 \mu \mathrm{m}$ particle size $)$ using gradient elution at a flow rate of $0.35 \mathrm{~mL} / \mathrm{min}$. Mobile phase A consisted of $0.1 \mathrm{M}$ ammonium formate (adjusted to $\mathrm{pH}$ 6.0 with $1 \%$ acetic acid), and mobile phase B consisted of $90 \%$ solvent A with $10 \%$ methanol. The solvent gradient was $100 \%$ solvent A increasing to $5 \%$ solvent $\mathrm{B}$ at $2 \mathrm{~min}$, then to $60 \%$ solvent B at $4.5 \mathrm{~min}$ before returning to $100 \%$ solvent $\mathrm{A}$ at $4.55 \mathrm{~min}$ with column re-equilibration through to $6 \mathrm{~min}$. Total toxicity was reported as $\mathrm{STX} \cdot 2 \mathrm{HCl}$ eq using TEFs based on Oshima data using averaged toxicities of combined epimers, neosaxitoxin (NEO) oral toxicity (31), and several other exceptions.

(c) Laboratory C.-PSTs were extracted from $5.0 \pm 0.1 \mathrm{~g}$ shellfish homogenate. A volume of $3 \mathrm{~mL}$ of $1 \%$ acetic acid was added and the mixture mixed on the vortex mixer for $90 \mathrm{~s}$. The samples were placed in a boiling water bath for $20 \mathrm{~min}$ and 
cooled in running cold water for $5 \mathrm{~min}$ before mixing on the vortex mixer for $90 \mathrm{~s}$ and centrifugation at $3600 \times g$ for $5 \mathrm{~min}$. The supernatant was recovered, the pellet was resuspended in $3 \mathrm{~mL}$ of $1 \%$ acetic acid, and the solution was mixed on the vortex mixer and centrifuged again. Both supernatants were combined and diluted to a $10 \mathrm{~mL}$ volume with deionized water. Sample extracts were cleaned up using SPE cartridges (Phenomenex Strata-X, $200 \mathrm{mg} / 3 \mathrm{~mL}$ ). The UPLC method was carried out on a Waters Acquity UPLC instrument coupled with a Waters Acquity FLD (excitation, $340 \mathrm{~nm}$; emission, $395 \mathrm{~nm}$ ). Chromatographic separation was carried out on an Agilent Polaris $3 \mathrm{C} 18$ ether column $(100 \times 2.0 \mathrm{~mm}$ id $)$ using gradient elution at a flow rate of $0.5 \mathrm{~mL} / \mathrm{min}$. Mobile phase A consisted of $10 \mathrm{mM}$ ammonium formate with $0.04 \%$ acetic acid, and mobile phase B was $10 \mathrm{mM}$ ammonium formate with 5\% acetonitrile and $0.04 \%$ acetic acid. The solvent gradient was $100 \%$ solvent A for $1 \mathrm{~min}$, increasing to $5 \%$ solvent $\mathrm{B}$ at $3.5 \mathrm{~min}$, and then to $30 \%$ solvent $\mathrm{B}$ at $5 \mathrm{~min}$ before returning to $100 \%$ solvent $\mathrm{A}$ at $5.6 \mathrm{~min}$ with column re-equilibration through to $8 \mathrm{~min}$. Total toxicity was reported as STX equivalents (not as $2 \mathrm{HCl}$ salt) and calculated using TEFs derived from Oshima (31), except for decarbamoylgonyautoxin 2\&3 (dcGTX2\&3), which was subsequently re-examined by Quilliam (33). TEFs of the analogs with higher toxicity were used for those epimers that were combined.

\section{Statistical Analysis}

All statistical analyses were performed using $R$ software ( $R$ Core Development Team, Version 3.1.3; 2015). In accordance with AOAC's Guidelines for Validation of Qualitative Binary Chemistry Methods, the statistical analysis of this interlaboratory study was based on methods outlined in Wehling et al., Labudde and Harnly, and Macarthur and von Holst (34-36). Laboratory POD (LPOD) is the composite POD pooled across laboratories and includes between-laboratory variation in addition to variation inherent in the binomial nature of the binary probabilities. In addition to an estimate of the average POD across laboratories, 95\% confidence intervals were also calculated for the LPOD (34).

To assess the variability in the interlaboratory results, the reproducibility SD (within-laboratory variation pooled across all laboratories), laboratory SD (between-laboratory variation), and $S_{R}$ (variability between single test results obtained in different laboratories) were calculated. The homogeneity test of LPODs was also applied to assess whether there was any detected intercollaborator effect (35).

For each matrix and protocol combination, linear interpolation was used to estimate the LPOD and 95\% prediction interval at the regulatory level of $0.8 \mathrm{mg} \mathrm{STX} \cdot 2 \mathrm{HCl} \mathrm{eq} / \mathrm{kg}$, as well as the LOD at a $95 \%$ POD. A logistic regression model was also fitted to the data in order to relate observed LPODs across experimental concentration levels, and this model was interpolated for specified concentration levels and to estimate LPODs and LODs.

\section{Results and Discussion}

The toxin profile of the shellfish homogenates used in this study comprised a range of STX analogs. The three oyster homogenates originated from Tasmanian A. tamarense (group 1) blooms occurring in 2015 and 2016. One homogenate was not modified and was dominated by the PST analog GTX2\&3 (67\% of total $\mathrm{mg} \mathrm{STX} \cdot 2 \mathrm{HCl} \mathrm{eq} / \mathrm{kg}$; all percentages reported herein represent the contribution of each PST analog to total toxicity). The two other oyster homogenates were spiked with PSTcertified standards to mimic profiles observed in other parts of the world. One sample was spiked with STX to contain similar levels of GTX2\&3, GTX1\&4, and STX; the other homogenate was spiked with GTX1\&4 to ensure dominance by this analog. These toxin profiles resemble those commonly found in the Gulf of Maine (United States) and the United Kingdom, respectively $(15,16,22)$. Mussel homogenates also contained variable toxin profiles, and they were not modified or spiked because they originated from different blooms. One mussel homogenate originated from a G. catenatum bloom dominated by dcSTX (50\%), another originated from the same A. tamarense bloom as the oyster homogenates (2015; dominated by GTX2\&3 at 50\%), and the third mussel homogenate originated from an $A$. tamarense bloom that occurred in Tasmania in 2012, which was dominated by GTX2\&3 and STX (Table 1).

\section{LC Analysis}

This study highlights the variability in reporting total PST levels in shellfish for monitoring programs because each laboratory used different calculations to obtain STX equivalency. One laboratory reported in $\mathrm{mg}$ STX eq $/ \mathrm{kg}$ (not as $2 \mathrm{HCl}$ salt) using TEFs derived from Oshima and Quilliam (31, 33), following the requirements of the Australian New Zealand Food Standards Code (6) and using the TEFs of analogs with greater toxicity for those that were combined. The two other laboratories reported in $\mathrm{mg} \mathrm{STX} \cdot 2 \mathrm{HCl} \mathrm{eq} / \mathrm{kg}$; one laboratory used TEFs recommended by the European Scientific Panel on Contaminants in the Food Chain (30), and the other laboratory used TEFs based on Oshima and Quilliam with averaged toxicities of combined epimers, and a higher TEF for neosaxitoxin based on oral toxicity (32). Results reported by the three laboratories were harmonized to $\mathrm{mg} \mathrm{STX} \cdot 2 \mathrm{HCl} \mathrm{eq} / \mathrm{kg}$ using the TEFs recommended jointly by the FAO/WHO (29) in order to make all results comparable (Table 1; refer to the SLV study of the Neogen kit for differences in TEFs by Oshima, EFSA, and FAO/WHO; 26).

Results obtained from most shellfish homogenates were higher than expected for each targeted concentration (initial PST concentration based on data from the routine monitoring program using the PreCOX method). The total toxicity returned by the three laboratories showed variability (Table 1), particularly at high PST concentrations (targeted at $0.8 \mathrm{mg} \mathrm{STX} \cdot 2 \mathrm{HCl} \mathrm{eq} / \mathrm{kg}$ ), ranging from 0.758 to $1.217 \mathrm{mg} \mathrm{STX} \cdot 2 \mathrm{HCl} \mathrm{eq} / \mathrm{kg}$ for oysters (average of $0.970 \pm$ $0.231 \mathrm{mg} \mathrm{STX} \cdot 2 \mathrm{HCl} \mathrm{eq} / \mathrm{kg}$ ) and 0.888 to $1.362 \mathrm{mg} \mathrm{STX} \cdot 2 \mathrm{HCl}$ eq $/ \mathrm{kg}$ for mussels (average of $1.126 \pm 0.237 \mathrm{mg} \mathrm{STX} \cdot 2 \mathrm{HCl} \mathrm{eq} / \mathrm{kg}$ ). Additionally, there were some differences observed in the toxin profile reported for four of the six contaminated homogenates. For the oyster homogenate targeted at $0.2 \mathrm{mg} \mathrm{STX} \cdot 2 \mathrm{HCl} \mathrm{eq} / \mathrm{kg}$, Laboratories A and B found 34 and $24 \%$ of GTX1\&4 and 54 and $60 \%$ of GTX2\&3, respectively; however, Laboratory $\mathrm{C}$ did not find any GTX1\&4, but reported $86 \%$ of GTX $2 \& 3$. For the oyster homogenate at $0.8 \mathrm{mg}$ $\mathrm{STX} \cdot 2 \mathrm{HCl} \mathrm{eq} / \mathrm{kg}$, the three laboratories detected GTX1\&4, GTX2\&3, and N-sulfocarbamoylgonyautoxin 2\&3 (C1\&2), but Laboratory A also reported STX, although at low levels (1\%). The highest variability was observed on mussel homogenates. For the mussel homogenate targeted at $0.2 \mathrm{mg} \mathrm{STX} \cdot 2 \mathrm{HCl}$ eq $/ \mathrm{kg}$, 
Table 1. Total PST and average toxin profile of naturally contaminated mixes used in the present study determined by Official Method $^{\text {SM }} 2005.06$ performed by three participant laboratories, calculated using FAO/WHO TEFs

\begin{tabular}{|c|c|c|c|c|c|c|c|c|}
\hline \multirow[b]{2}{*}{ Matrix } & \multirow{2}{*}{$\begin{array}{l}\text { Bloom source (all from } \\
\text { Tasmania, Australia) }\end{array}$} & \multirow{2}{*}{$\begin{array}{c}\text { Target,mg } \\
\mathrm{STX} \cdot 2 \mathrm{HCl} \text { eq } / \mathrm{kg}\end{array}$} & \multicolumn{5}{|c|}{ Total PST, mg STX·2HCl eq $/ \mathrm{kg}$} & \multirow{2}{*}{$\begin{array}{l}\text { Avg. toxin profile, \% of total; } \\
\text { mg STX } 2 \mathrm{HCl} \text { eq } / \mathrm{kg}\end{array}$} \\
\hline & & & Lab A & Lab B & Lab C & Mean $^{a}$ & SD & \\
\hline \multirow[t]{10}{*}{ Oyster } & Nil & 0.0 & $<0.025$ & $<0.025$ & $<0.025$ & $<0.025$ & $N A^{b}$ & NA \\
\hline & Alexandrium tamarense & 0.2 & 0.248 & 0.271 & 0.239 & 0.253 & 0.017 & $67 \%$ GTX2\&3 \\
\hline & complex $2015^{c}$ & & & & & & & $29 \%$ GTX1\&4 \\
\hline & & & & & & & & $13 \%$ C1\&2 \\
\hline & A. tamarense complex 2015 \& & 0.6 & 0.721 & 0.752 & 0.744 & 0.739 & 0.016 & $33 \%$ GTX2\&3 \\
\hline & 2016 + spiked with STX standard & & & & & & & $32 \%$ GTX1\&4 \\
\hline & & & & & & & & $26 \%$ STX \\
\hline & & & & & & & & $9 \% \mathrm{C} 1 \& 2$ \\
\hline & A. tamarense complex $2015+$ & 0.8 & 0.935 & 0.758 & 1.217 & 0.970 & 0.231 & $58 \%$ GTX $1 \& 4$ \\
\hline & spiked with GTX1\&4 standard $^{d}$ & & & & & & & $31 \%$ GTX2\&3 \\
\hline \multirow[t]{12}{*}{ Mussel } & Nil & 0.0 & $<0.025$ & $<0.025$ & $<0.025$ & $<0.025$ & NA & NA \\
\hline & Gymnodinium catenatum $2015^{e}$ & 0.2 & 0.130 & 0.231 & 0.296 & 0.219 & 0.084 & $50 \%$ dcSTX \\
\hline & & & & & & & & $24 \%$ dcGTX2\&3 \\
\hline & & & & & & & & $13 \%$ C $1 \& 2$ \\
\hline & A. tamarense complex $2015^{d}$ & 0.6 & 0.705 & 0.785 & 0.603 & 0.698 & 0.091 & $50 \%$ GTX2\&3 \\
\hline & & & & & & & & $41 \%$ GTX1\&4 \\
\hline & & & & & & & & $8 \% \mathrm{C} 1 \& 2$ \\
\hline & A. tamarense complex $2012^{f}$ & 0.8 & 0.888 & 1.362 & 1.130 & 1.126 & 0.237 & $48 \%$ GTX2\&3 \\
\hline & & & & & & & & $37 \%$ STX \\
\hline & & & & & & & & $10 \%$ C1\&2 \\
\hline & & & & & & & & $2 \%$ GTX5 \\
\hline & & & & & & & & $2 \%$ dcGTX2\&3 \\
\hline
\end{tabular}

\footnotetext{
a Only PST analogs found in common by two or three laboratories were used for the average calculations.

$b \quad \mathrm{NA}=$ Not available.

c Lab C did not detect GTX1\&4, but returned higher levels of GTX2\&3.

d Lab A also found STX at 1 and $4 \%$ in oyster and mussel mixes, respectively.

e Lab A also detected gonyautoxin 5 (GTX5) (1.5\%); Lab B also found N-sulfocarbamoylgonyautoxin 1\&4 (C3\&4) (11.5\%); and Lab C detected GTX1\&4 (39\%), but not C1\&2, and lesser levels of decarbamoylsaxitoxin (dcSTX) (37\%) compared with the other two laboratories.

$f$ Lab A also detected dcSTX (0.6\%); Lab B found GTX1\&4 (6.7\%), but not dcGTX2\&3; and Lab C did not detect GTX5.
}

Laboratories A and B reported similar levels of dcSTX, dcGTX2\&3, and C1\&2, but laboratory A also detected GTX5 (1.5\%) and Laboratory B reported C3\&4 (11.5\%). Further, Laboratory C detected $39 \%$ of GTX1\&4 (the other two laboratories did not detect this PST analog) and did not detect $\mathrm{C} 1 \& 2$. For the mussel homogenate at $0.8 \mathrm{mg}$ $\mathrm{STX} \cdot 2 \mathrm{HCl} \mathrm{eq} / \mathrm{kg}$, the three laboratories similarly reported GTX2\&3, STX, and C1\&2; however, Laboratory A also reported dcSTX $(0.6 \%)$, dcGTX2\&3 (1\%; together with Laboratory C at 4\%), and GTX5 (together with Laboratory $\mathrm{B}$ at $2 \%$ ), whereas Laboratory B was the only laboratory to detect GTX1\&4 (6.7\%), but not dcGTX2\&3. These results confirm the limitation of the Pre-COX method in quantifying GTX1\&4, especially when other PST analogs are present in the sample. Previous work reports an overestimation of this PST analog compared with the PCOX or HILIC-MS/MS methods $(37,38)$.

Oyster and mussel homogenates from the $A$. tamarense 2015 bloom showed slightly different toxin profiles. Oysters contained predominantly GTX2\&3 (67\%), followed by GTX1\&4 (29\%) and C1\&2 (13\%); in contrast, mussels had GTX2\&3 (50\%), GTX1\&4 (41\%), and C1\&2 (8\%). The toxin profile of an algal net sample from this bloom was dominated by GTX1\&4 (70\%), with lesser amounts of GTX2\&3 (15\%) and C1\&2 (12\%). This suggests a higher capacity of oysters to convert more toxic congeners, such as GTX1\&4, to the less toxic GTX2\&3, and thus leading to a decrease in total toxicity. Similar observations were found in PST-contaminated C. gigas oysters and M. galloprovincialis mussels from Korea and the Mediterranean (Bizerte Lagoon). Korean mussels contained higher proportions of GTX1\&4 (65-71\%) and less GTX2\&3 $(4 \%)$, with higher total toxicity than oysters (GTX1\&4 = $41-42 \%$; GTX2\&3 = 17-22\%; 39). In contrast, oysters from the Mediterranean did not contain GTX1\&4 (dominated by $\mathrm{C} 1 \& 2=72 \%$ and GTX5 $=27 \%$ ), but mussels contained GTX1\&4 (11\%), with lesser levels of C1\&2 (47\%; GTX5 = $28 \%$ ), accounting for higher total toxicities that were also maintained for longer periods (40). Biotransformation of PSTs has been previously reported and varies among species of molluscs; for instance, M. edulis mussels showed a lower capacity for PST transformation than clams (41), but king scallops showed a much higher biotransformation capacity than Pacific oysters (42). The role of enzymes and bacteria in the transformation of PST underpins detoxification processes 
by shellfish $(43,44)$. In this study, the use of the amino acid L-cysteine in the modified protocol allowed conversion of GTX1\&4 and GTX2\&3 congeners to neosaxitoxin (NEO) and STX, respectively, to increase the cross-reactivity of the Neogen test.

\section{Rapid Test Kit Results}

Although samples were sent to 17 laboratories, 1 laboratory had issues with import certifications and only 16 laboratories were able to perform the tests. Laboratories returned results for six replicates of each sample, with the exception of one laboratory that spilled one replicate. Thus, each concentration in each matrix measured by each protocol had 96 replicate results, except the $0.74 \mathrm{mg} \mathrm{STX} \cdot 2 \mathrm{HCl} \mathrm{eq} / \mathrm{kg}$ oyster sample measured via the modified protocol, which had 95 replicates (Table 2).

\section{Standard Protocol}

All laboratories returned negative results for all the samples in both matrixes when PST levels were $<0.025 \mathrm{mg} \mathrm{STX} \cdot 2 \mathrm{HCl}$ eq/ $\mathrm{kg}$. Almost all laboratories reported six out of six positive results in all oyster replicates when the analytical method indicated the PST level was $\geq 0.74 \mathrm{mg} \mathrm{STX} \cdot 2 \mathrm{HCl} \mathrm{eq} / \mathrm{kg}$; only one laboratory reported five out of six positive results at $0.97 \mathrm{mg} \mathrm{STX} \cdot 2 \mathrm{HCl}$ eq/ $\mathrm{kg}$. With mussels, laboratories reported six out of six positives at PST concentrations $\geq 0.70 \mathrm{mg} \mathrm{STX} \cdot 2 \mathrm{HCl} \mathrm{eq} / \mathrm{kg}$, with the exception of one laboratory reporting two out of six positives at $0.70 \mathrm{mg} \mathrm{STX} \cdot 2 \mathrm{HCl} \mathrm{eq} / \mathrm{kg}$ and another reporting five out of six positives at $1.13 \mathrm{mg} \mathrm{STX} \cdot 2 \mathrm{HCl} \mathrm{eq} / \mathrm{kg}$ (Table 2). The strong homogeneity of results from the different laboratories in each matrix at low and high PST levels (below detection and above the regulatory limit by the analytical method) is shown by the low $\mathrm{s}_{\mathrm{r}}$, laboratory SDs, and $\mathrm{s}_{\mathrm{R}}(<0.5$; Table 3$)$.
The LPOD of PST in each matrix at each concentration is summarized in Table 3, along with $95 \%$ confidence limits. The LPOD in oysters using the standard protocol was relatively low $(0.18)$ at the $0.25 \mathrm{mg} \mathrm{STX} \cdot 2 \mathrm{HCl} \mathrm{eq} / \mathrm{kg}$ concentration. LPOD increased as the PST level increased and was $\geq 0.99$ at PST concentrations above $0.70 \mathrm{mg} \mathrm{STX} \cdot 2 \mathrm{HCl} \mathrm{eq} / \mathrm{kg}$. In contrast, the test was shown to be highly sensitive for mussels with high POD at relatively low PST levels. The LPOD was $\geq 0.95$ for all PST concentrations above $0.20 \mathrm{mg} \mathrm{STX} \cdot 2 \mathrm{HCl} \mathrm{eq} / \mathrm{kg}$ (Table 3 and Figure 1). These results indicate positive detections will occur at PST concentrations well below the regulatory limit when using the LFIA Neogen kit with the standard protocol in mussels, similar to the SRT kit, although not at very low PST concentrations (i.e., $<0.20 \mathrm{mg} \mathrm{STX} \cdot 2 \mathrm{HCl} \mathrm{eq} / \mathrm{kg})(14,15,23)$. The homogeneity test at these PST levels showed no significant difference between laboratories $(P>0.05)$, indicating the method is reproducible at these levels. For oysters, the homogeneity test showed the method was also reproducible at the $0.74 \mathrm{mg}$ $\mathrm{STX} \cdot 2 \mathrm{HCl} \mathrm{eq} / \mathrm{kg}$ level; however, this was not the case for mussels at $0.70 \mathrm{mg} \mathrm{STX} \cdot 2 \mathrm{HCl} \mathrm{eq} / \mathrm{kg}$ due to Laboratory 8 only returning two out of six positives (Table 2).

Within-laboratory reproducibility was used to estimate prediction intervals within which $95 \%$ of laboratories are expected to give a positive result. The prediction intervals are shown in Figure 2 alongside the individual POD for each laboratory for each concentration. As expected from Figure 1, the LPOD obtained for mussels was higher than for oysters using the standard protocol, with an estimated LPOD of 0.95 at $0.22 \mathrm{mg} \mathrm{STX} \cdot 2 \mathrm{HCl} \mathrm{eq} / \mathrm{kg}$ in mussels, and an estimated LPOD of 0.18 at $0.25 \mathrm{mg}$ $\mathrm{STX} \cdot 2 \mathrm{HCl} \mathrm{eq} / \mathrm{kg}$ in oysters.

Linear interpolation of the LPOD curves was used to estimate the LOD, the LPOD at the regulatory limit of $0.8 \mathrm{mg} \mathrm{STX} \cdot 2 \mathrm{HCl} \mathrm{eq} / \mathrm{kg}$, and the $95 \%$ prediction interval at this value (Table 4). The estimated LOD for mussels was $0.316 \mathrm{mg} \mathrm{STX} \cdot 2 \mathrm{HCl} \mathrm{eq} / \mathrm{kg}$, less than half the regulatory limit,

Table 2. Number of positive test results from six replicates recorded by all the laboratories ${ }^{a}$

\begin{tabular}{|c|c|c|c|c|c|c|c|c|c|c|c|c|c|c|c|c|c|c|}
\hline \multirow[b]{2}{*}{ Protocol } & \multirow[b]{2}{*}{ Matrix } & \multirow[b]{2}{*}{ Total PST, mg STX·2HCl eq $/ \mathrm{kg}^{b}$} & \multicolumn{16}{|c|}{ No. of participant labs } \\
\hline & & & 1 & 2 & 3 & 4 & 5 & 6 & 7 & 8 & 9 & 10 & 11 & 12 & 13 & 14 & 15 & 16 \\
\hline \multirow[t]{8}{*}{ Standard } & Oyster & $<0.025$ & 0 & 0 & 0 & 0 & 0 & 0 & 0 & 0 & 0 & 0 & 0 & 0 & 0 & 0 & 0 & 0 \\
\hline & & 0.25 & 2 & 3 & 0 & 0 & 2 & 2 & 0 & 0 & 3 & 0 & 3 & 0 & 0 & 0 & 2 & 0 \\
\hline & & 0.74 & 6 & 6 & 6 & 6 & 6 & 6 & 6 & 6 & 6 & 6 & 6 & 6 & 6 & 6 & 6 & 6 \\
\hline & & 0.97 & 5 & 6 & 6 & 6 & 6 & 6 & 6 & 6 & 6 & 6 & 6 & 6 & 6 & 6 & 6 & 6 \\
\hline & Mussel & $<0.025$ & 0 & 0 & 0 & 0 & 0 & 0 & 0 & 0 & 0 & 0 & 0 & 0 & 0 & 0 & 0 & 0 \\
\hline & & 0.22 & 6 & 5 & 6 & 6 & 6 & 6 & 6 & 4 & 6 & 6 & 6 & 6 & 4 & 6 & 6 & 6 \\
\hline & & 0.70 & 6 & 6 & 6 & 6 & 6 & 6 & 6 & 2 & 6 & 6 & 6 & 6 & 6 & 6 & 6 & 6 \\
\hline & & 1.13 & 5 & 6 & 6 & 6 & 6 & 6 & 6 & 6 & 6 & 6 & 6 & 6 & 6 & 6 & 6 & 6 \\
\hline \multirow[t]{8}{*}{ Modified } & Oyster & $<0.025$ & 0 & 0 & 0 & 0 & 0 & 0 & 0 & 0 & 0 & 0 & 0 & 0 & 0 & 0 & 0 & 0 \\
\hline & & 0.25 & 3 & 2 & 2 & 0 & 2 & 2 & 0 & 1 & 3 & 0 & 2 & 0 & 2 & 1 & 6 & 0 \\
\hline & & 0.74 & 6 & 6 & 6 & 5 & 6 & $5^{c}$ & 6 & 6 & 5 & 6 & 6 & 4 & 6 & 6 & 6 & 6 \\
\hline & & 0.97 & 6 & 6 & 6 & 6 & 6 & 6 & 6 & 6 & 6 & 6 & 6 & 6 & 6 & 6 & 6 & 5 \\
\hline & Mussel & $<0.025$ & 0 & 0 & 0 & 0 & 1 & 0 & 0 & 0 & 0 & 0 & 0 & 0 & 0 & 0 & 0 & 0 \\
\hline & & 0.22 & 5 & 6 & 6 & 1 & 6 & 2 & 5 & 4 & 5 & 4 & 6 & 5 & 5 & 4 & 5 & 1 \\
\hline & & 0.70 & 6 & 6 & 6 & 5 & 6 & 6 & 6 & 6 & 6 & 6 & 6 & 6 & 6 & 6 & 6 & 3 \\
\hline & & 1.13 & 6 & 6 & 6 & 6 & 6 & 6 & 6 & 6 & 6 & 6 & 6 & 6 & 6 & 6 & 6 & 6 \\
\hline
\end{tabular}

\footnotetext{
a Participant numbers were randomly assigned and are not linked to the author list affiliation.

b Total PST shown is the average obtained from three laboratories performing the analytical method (as per Table 1).

$c$ Five replicates only due to a spillage of one replicate.
} 
Table 3. Estimated parameters summarizing the results obtained by the 16 laboratories

\begin{tabular}{|c|c|c|c|c|c|c|c|c|c|}
\hline Protocol & Matrix & $\begin{array}{c}\text { Total PST,mg } \\
\mathrm{STX} \cdot 2 \mathrm{HCl} \text { eq } / \mathrm{kg}\end{array}$ & No. of replicates & No. of positives & $\operatorname{LPOD}(95 \% \mathrm{Cl})^{a}$ & $\mathrm{~s}_{\mathrm{r}}$ & Lab SDs & $\mathrm{S}_{\mathrm{R}}$ & Homogeneity test of LPODs \\
\hline \multirow[t]{7}{*}{ Standard } & Oyster & $<0.025$ & 96 & 0 & $0(0,0.038)$ & 0 & 0 & 0 & $N A^{b}$ \\
\hline & & 0.25 & 96 & 17 & $0.18(0.069,0.285)$ & 0.351 & 0.160 & 0.386 & 0.019 \\
\hline & & 0.74 & 96 & 96 & $1(0.962,1.0)$ & 0 & 0 & 0 & NA \\
\hline & & 0.97 & 96 & 95 & $0.99(0.943,0.998)$ & 0.102 & 0 & 0.102 & 0.44 \\
\hline & & 0.22 & 96 & 91 & $0.95(0.884,0.978)$ & 0.209 & 0.081 & 0.224 & 0.049 \\
\hline & & 0.70 & 96 & 92 & $0.96(0.898,0.984)$ & 0.129 & 0.158 & 0.204 & $<0.0001$ \\
\hline & & 1.13 & 96 & 95 & $0.99(0.943,0.998)$ & 0.102 & 0 & 0.102 & 0.44 \\
\hline \multirow[t]{7}{*}{ Modified } & Oyster & $<0.025$ & 96 & 0 & $0(0,0.038)$ & 0 & 0 & 0 & NA \\
\hline & & 0.25 & 96 & 26 & $0.27(0.137,0.405)$ & 0.398 & 0.209 & 0.449 & 0.007 \\
\hline & & 0.97 & 96 & 95 & $0.99(0.943,0.998)$ & 0.102 & 0 & 0.102 & 0.44 \\
\hline & Mussel & $<0.025$ & 96 & 1 & $0.01(0.002,0.057)$ & 0.102 & 0 & 0.102 & 0.44 \\
\hline & & 0.22 & 96 & 70 & $0.73(0.587,0.871)$ & 0.387 & 0.229 & 0.450 & 0.002 \\
\hline & & 0.70 & 96 & 92 & $0.96(0.90,0.984)$ & 0.171 & 0.109 & 0.202 & 0.001 \\
\hline & & 1.13 & 96 & 96 & $1.0(0.962,1.0)$ & 0 & 0 & 0 & NA \\
\hline
\end{tabular}

\footnotetext{
a $\mathrm{Cl}=$ Confidence interval.
}

b NA $=$ Not applied.

although $95 \%$ of laboratories were predicted to have an estimated LOD in mussels of less than $1.113 \mathrm{mg}$ $\mathrm{STX} \cdot 2 \mathrm{HCl} \mathrm{eq} / \mathrm{kg}$. The estimated LOD for oysters displayed a narrower range, with an average LOD of 0.710 and with $95 \%$ of laboratories predicted to have an estimated LOD of less than $0.731 \mathrm{mg} \mathrm{STX} \cdot 2 \mathrm{HCl} \mathrm{eq} / \mathrm{kg}$. For both oysters and mussels, the LPOD at the regulatory level was high using the standard protocol $(>0.96)$.

The LPOD is a measure of the probability of a positive response at a given concentration, but for regulatory purposes, it is the probability of a negative response at the regulatory limit that is more relevant to public safety. Defined as the $\beta$-error, the laboratory probability of a negative response can be obtained by subtracting the LPOD from 1. European Commission (EC) Decision 2002/657/EC, section 2.2, requires that screening methods must be validated in a documented manner, and the $\beta$-error at the regulatory limit must be $<0.05$ if they are to be used in conformity with Directive 96/23/EC (45). The estimated $\beta$-error at the $0.8 \mathrm{mg} \mathrm{STX} \cdot 2 \mathrm{HCl} \mathrm{eq} / \mathrm{kg}$ level complied with this requirement for mussels and oysters using the standard protocol; however, the prediction interval for $95 \%$ of tests in mussels to record a negative response at this level covered a wide range $(0.000-0.237)$. Oysters showed a narrower $95 \%$ prediction interval, ranging from 0.000 to 0.033 .

The $\beta$-error was also obtained through the use of a logistic regression model. The model fit for results from the mussel matrix was poor due to the large number of positives at low PST concentrations and, therefore, not included in the analysis. The logistic regression model for the data obtained from the oyster matrixes (shown in Figure 3) was used to determine the LPOD expected at various PST concentrations (Table 5). The model estimates that the LFIA Neogen kit used in oysters with the

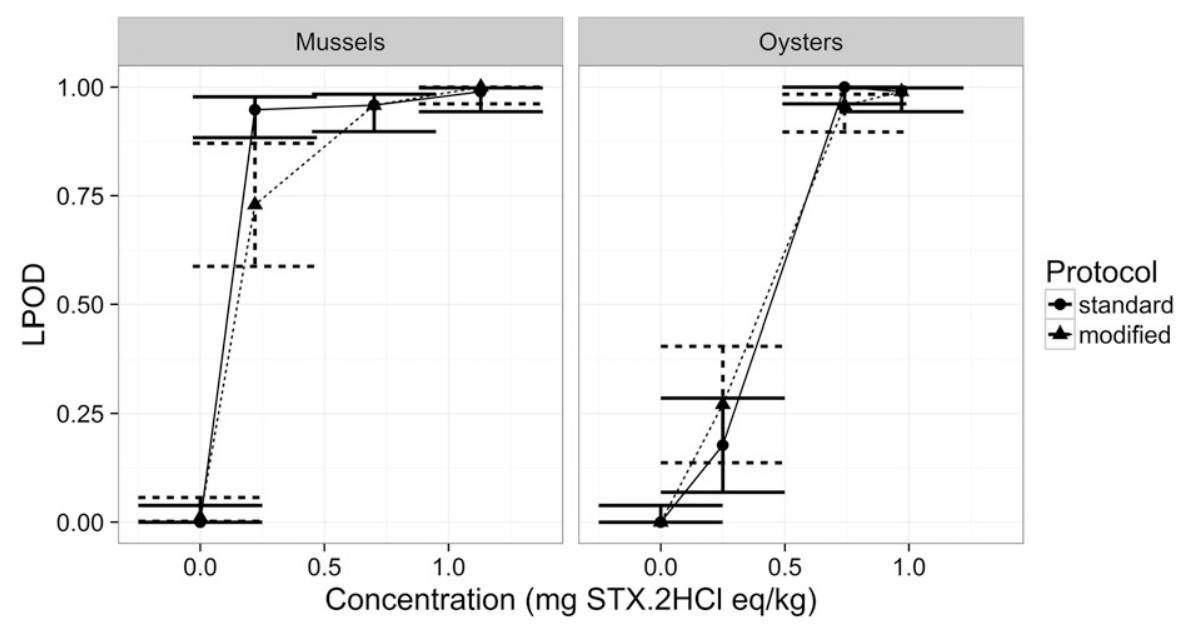

Figure 1. POD of PSTs in mussels and oysters at various PST concentrations by the Neogen kit using two protocols. 


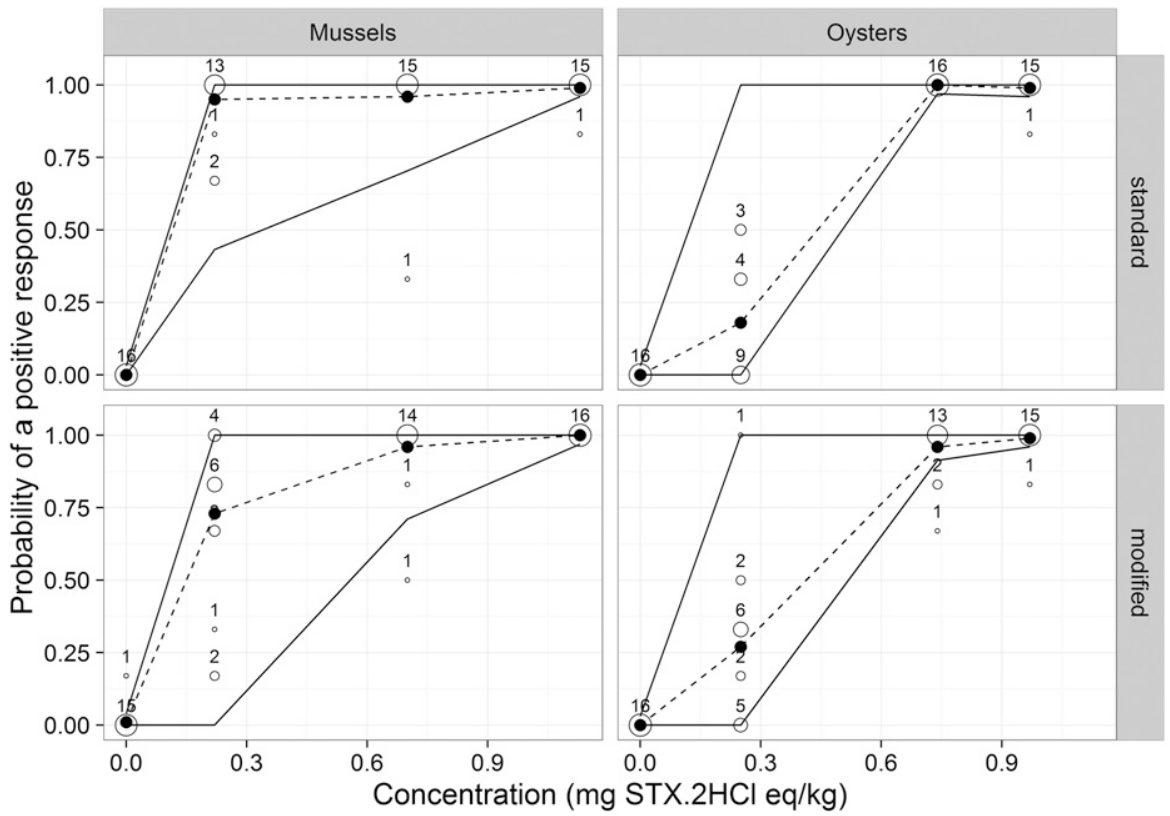

Figure 2. POD for all laboratories (black dots) for each matrix using the standard and modified protocols over a range of PST concentrations. Estimates of the average POD (dashed line) and the POD for the 5th and 95th percentile of laboratories (solid lines) are shown. Open circles indicate the number of laboratories with the same POD, and their size is proportional to the number of laboratories with number of each listed above each circle.

standard protocol will return a positive result at $0.8 \mathrm{mg}$ $\mathrm{STX} \cdot 2 \mathrm{HCl} \mathrm{eq} / \mathrm{kg} 100 \%$ of the time, and at $0.6 \mathrm{mg} \mathrm{STX} \cdot 2 \mathrm{HCl}$ eq $/ \mathrm{kg}$ will detect a positive response $94 \%$ of the time (i.e., a $\beta$-error of 0.00 and 0.06 , respectively). The LPOD at lower PST concentrations decreased, meaning the probability of a positive result occurring at half the regulatory limit is estimated to be 0.57 . The $\beta$-error at $0.8 \mathrm{mg} \mathrm{STX} \cdot 2 \mathrm{HCl} \mathrm{eq} / \mathrm{kg}$ estimated via modeling was similar but slightly lower than that estimated via linear interpolation of the POD curves (0.003).

\section{Modified Protocol}

Similar to the standard protocol, laboratories returned zero out of six positive results for the samples at $<0.025 \mathrm{mg}$ $\mathrm{STX} \cdot 2 \mathrm{HCl} \mathrm{eq} / \mathrm{kg}$ in both matrixes, except for Laboratory 5 , which returned one positive result for the mussel homogenate. One laboratory reported five out of six positive results in the oyster matrix when the analytical method indicated the total PST level was $0.97 \mathrm{mg} \mathrm{STX} \cdot 2 \mathrm{HCl} \mathrm{eq} / \mathrm{kg}$; all other laboratories reported six out of six positives in both matrixes at this PST concentration. Results were more variable for both the oyster and mussel matrixes at the 0.74 and $0.70 \mathrm{mg} \mathrm{STX} \cdot 2 \mathrm{HCl} \mathrm{eq} / \mathrm{kg}$ concentrations, returning a total of 91 and 92 positive tests (out of 95 and 96), respectively. The strong homogeneity of results from all laboratories at negligible PST levels and PST levels above the regulatory limit is shown by the low $\mathrm{s}_{\mathrm{r}}$, laboratory SDs, and $\mathrm{s}_{\mathrm{R}}$, leading to the homogeneity test showing no significant difference between laboratories $(P>0.05)$. Thus, this protocol also resulted in reproducible results at these PST levels in both matrixes. As with the standard protocol, the homogeneity test showed the method was reproducible in oysters at $0.74 \mathrm{mg} \mathrm{STX} \cdot 2 \mathrm{HCl} \mathrm{eq} / \mathrm{kg}$, but not in mussels at a similar concentration (Table 3 ).

The LPOD and 95\% confidence limits of PST showed relatively high detection rates at low PST concentrations in mussels $(0.73$ LPOD at $0.22 \mathrm{mg} \mathrm{STX} \cdot 2 \mathrm{HCl}$ eq $/ \mathrm{kg}$; Table 3 ). Thus, a high number of positive results at PST concentrations below the regulatory limit are expected using this protocol on mussels, but less than with the standard protocol $(0.95 \mathrm{LPOD}$ at $0.22 \mathrm{mg} \mathrm{STX} \cdot 2 \mathrm{HCl} \mathrm{eq} / \mathrm{kg})$. The LPOD of the oyster homogenates was relatively low $(0.27)$ at the $0.25 \mathrm{mg} \mathrm{STX} \cdot 2 \mathrm{HCl} \mathrm{eq} / \mathrm{kg}$ concentration, and it also increased as PST levels increased ( $\geq 0.96$ for samples with PST concentrations $\geq 0.74 \mathrm{mg} \mathrm{STX} \cdot 2 \mathrm{HCl}$ eq $/ \mathrm{kg}$ ).

As with the standard protocol, the estimated LPOD in both matrixes complies with the requirement of EC Decision 2002/ $675 / \mathrm{EC}$ of having a $\beta$-error of $<0.05$ at the regulatory level. Again, the prediction interval for negative responses in $95 \%$ of tests in mussels covered a wide range (0.000-0.229); in contrast,

Table 4. LPODs at $0.8 \mathrm{mg} \mathrm{STX} \cdot 2 \mathrm{HCl}$ eq/kg (with $95 \%$ prediction intervals) and LODs calculated by linear interpolation

\begin{tabular}{|c|c|c|c|c|}
\hline \multirow[b]{2}{*}{ Protocol } & \multicolumn{2}{|c|}{ Mussels } & \multicolumn{2}{|c|}{ Oysters } \\
\hline & Estimated LPOD $(95 \% \mathrm{PI})^{a}$ & Estimated LOD ${ }^{\mathrm{b}}$ & Estimated LPOD (95\% PI) & Estimated LOD \\
\hline Standard & $0.966(0.763,1.00)$ & $0.316(1.113)$ & $0.997(0.967,1.00)$ & $0.710(0.731)$ \\
\hline Modified & $0.968(0.771,1.00)$ & $0.682(1.098)$ & $0.966(0.925,1.00)$ & $0.734(0.921)$ \\
\hline
\end{tabular}

\footnotetext{
a $\mathrm{PI}=$ Prediction interval.

b In parentheses: $95 \%$ of laboratories are predicted to have an LOD lower than the concentration shown.
} 


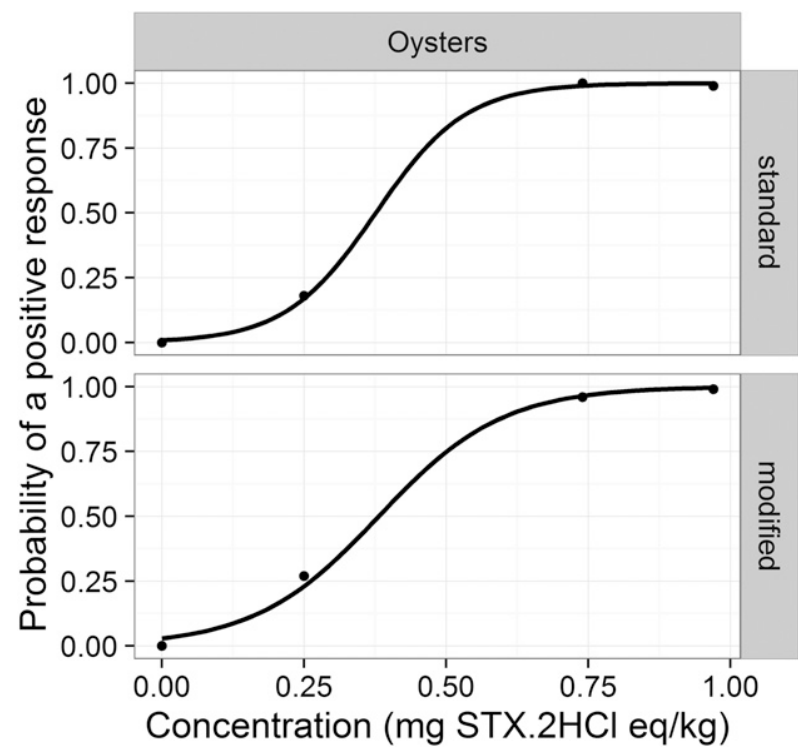

Figure 3. LPOD modeled by logistic regression across a range of PST concentrations in oysters using the LFIA Neogen kit with both the standard and modified protocols.

oysters showed a narrower $95 \%$ prediction interval $(0.000-0.075$; Table 4). The estimated LOD for both matrixes using the modified protocol was lower than the regulatory limit; however, $95 \%$ of laboratories were predicted to have an LOD of less than $1.098 \mathrm{mg} \mathrm{STX} \cdot 2 \mathrm{HCl} \mathrm{eq} / \mathrm{kg}$ for mussels and $0.921 \mathrm{mg} \mathrm{STX} \cdot 2 \mathrm{HCl}$ $\mathrm{eq} / \mathrm{kg}$ for oysters. LPOD calculations by logistic regression modeling for oysters using the modified protocol were 0.98 at $0.8 \mathrm{mg} \mathrm{STX} \cdot 2 \mathrm{HCl} \mathrm{eq} / \mathrm{kg}$. This translates to a $\beta$-error of 0.02 at $0.8 \mathrm{mg} \mathrm{STX} \cdot 2 \mathrm{HCl} \mathrm{eq} / \mathrm{kg}$, similar but slightly lower than that obtained via linear interpolation of the LPOD curves (0.034 at $0.8 \mathrm{mg} \mathrm{STX} \cdot 2 \mathrm{HCl} \mathrm{eq} / \mathrm{kg}$; Figure 3 ; the fit for mussels was poor and was not included). The LOD values estimated through modeling for oysters using both the standard and modified protocols were 0.60 and $0.70 \mathrm{mg} \mathrm{STX} \cdot 2 \mathrm{HCl} \mathrm{eq} / \mathrm{kg}$, respectively, which were lower than those estimated via interpolation and below the regulatory limit.

Jawaid et al. (25), who developed the Neogen kit (as per the standard protocol), observed that $\mathrm{STX} \cdot 2 \mathrm{HCl}$ (as an individual toxin standard) generated a positive response at a mean concentration $(n=3)$ of $0.68 \mathrm{mg} / \mathrm{kg}$, but they obtained

Table 5. LPODs for nominal PST concentrations in oysters calculated by binomial logistic regression modeling

\begin{tabular}{lcc}
\hline Protocol & PST, mg STX.2HCl eq/kg & LPOD \\
\hline Standard & 0.0 & 0.01 \\
& 0.2 & 0.10 \\
& 0.4 & 0.57 \\
& 0.6 & 0.94 \\
Modified & 0.8 & 1.00 \\
& 0.0 & 0.03 \\
& 0.2 & 0.16 \\
& 0.4 & 0.54 \\
& 0.6 & 0.88 \\
& 0.8 & 0.98 \\
\hline
\end{tabular}

positive results in mussels and oysters from 0.34 and $0.39 \mathrm{mg}$ $\mathrm{STX} \cdot 2 \mathrm{HCl}$ eq $/ \mathrm{kg}$, respectively (values recalculated using TEFs recommended by the $\mathrm{FAO} / \mathrm{WHO}$ ). In contrast, Harrison et al. (16) obtained positive results from concentrations of 0.43 and $0.49 \mathrm{mg} \mathrm{STX} \cdot 2 \mathrm{HCl}$ eq $/ \mathrm{kg}$ in oysters and mussels, respectively, using the Neogen test with the standard protocol (values calculated from their positive results showing the percentages of individual PST analogs and total toxicity using FAO/WHO TEFs). Dorantes-Aranda et al. (17) observed positive results from concentrations of $0.40 \mathrm{mg} / \mathrm{kg}$ for STX $\cdot 2 \mathrm{HCl}$ individual toxin standard, which correlates better with the findings of Harrison et al. compared with Jawaid et al. when they used individual $\mathrm{STX} \cdot 2 \mathrm{HCl}$ toxin standard, but correlates well with Jawaid et al.'s oyster sample positive results (from $0.39 \mathrm{mg}$ $\mathrm{STX} \cdot 2 \mathrm{HCl} \mathrm{eq} / \mathrm{kg}$ ). Dorantes-Aranda et al. modified the dilution for the toxin extraction step to alter the Neogen test to obtain positive results from 0.50 to $0.60 \mathrm{mg} \mathrm{STX} \cdot 2 \mathrm{HCl} \mathrm{eq} / \mathrm{kg}$ and observed positive results in mussels and oysters from 0.53 and $0.73 \mathrm{mg} \mathrm{STX} \cdot 2 \mathrm{HCl} \mathrm{eq} / \mathrm{kg}$, respectively (modified Neogen protocol, but without the conversion step). However, four positive results (13\%) were also obtained at $0.04-0.35 \mathrm{mg}$ $\mathrm{STX} \cdot 2 \mathrm{HCl} \mathrm{eq} / \mathrm{kg}$ in oysters (false-noncompliant). These observations confirm the findings of the single-laboratory study of the Neogen test (26) in which $100 \%$ of positive results were obtained for mussels and oysters at $>0.4$ and $>0.7 \mathrm{mg} \mathrm{STX} \cdot 2 \mathrm{HCl} \mathrm{eq} / \mathrm{kg}$, respectively. The low LOD calculated for mussels by linear interpolation using the standard protocol in the present interlaboratory study $(0.316 \mathrm{mg} \mathrm{STX} \cdot 2 \mathrm{HCl} \mathrm{eq} / \mathrm{kg})$ is close to the concentration from which Jawaid et al. (25) obtained positive results in mussels $(0.34 \mathrm{mg} \mathrm{STX} \cdot 2 \mathrm{HCl} \mathrm{eq} / \mathrm{kg}$; but not described as an LOD). This was also supported by the single-laboratory study in which a POD of $\geq 0.9$ was obtained for mussels with $\geq 0.25 \mathrm{mg}$ $\mathrm{STX} \cdot 2 \mathrm{HCl} \mathrm{eq} / \mathrm{kg}$.

The toxin profile variability of the shellfish homogenates used in this study may have influenced obtaining a lower LOD for mussels compared with oysters when using the standard protocol. At the lowest PST level $(0.2 \mathrm{mg} \mathrm{STX} \cdot 2 \mathrm{HCl} \mathrm{eq} / \mathrm{kg})$, mussels were dominated with dcSTX (by $50 \%$, originating from a $G$. catenatum bloom), whereas oysters were predominantly contaminated with GTX2\&3 (by $67 \%$, originating from an $A$. tamarense bloom). Given that the cross-reactivity of the Neogen test for these two PST analogs were 56 and 23\%, respectively, a higher number of positives in mussels at low PST levels was observed, which may have led to an estimation of a lower LOD using the standard protocol. In the SLV of the Neogen test, which used the modified protocol in dilution series of varying toxin profiles in mussels and oysters, it was observed, however, that the difference in POD was due to matrix differences, as opposed to the toxin profile (26). This suggests that the toxin profile had an impact only when using the standard protocol in which no conversion of PST occurred, and dcSTX and GTX2\&3 were present compared with the modified protocol in which GTX2\&3 was hydrolyzed to STX (46) in order to increase reactivity from 23 to $100 \%$ (supported by oyster LPOD values of 0.18 and 0.27 for standard and modified protocols, respectively, at $0.25 \mathrm{mg} \mathrm{STX} \cdot 2 \mathrm{HCl} \mathrm{eq} / \mathrm{kg}$; Table 3). (Note: GTX1\&4 is converted to NEO using the modified protocol, but this analog was not present in the mussel matrix containing dcSTX and GTX2\&3.) Conversion of GTX1\&4 and GTX2\&3 to NEO and STX, respectively, involves the reduction of the $O$-sulfate group (46); it is unclear, however, what the conversion products of dcSTX are, although the analog Gymnodinium catenatum toxin 3 (GC3) has 
been found as a hydroxybenzoate derivate of dcSTX, whereas Gymnodinium catenatum toxin 1 and 2 (GC1 and GC2) are hydroxysulfate derivates of Gymnodinium catenatum toxin 3 (47). Despite the fact that the toxicity of these new derivates is still to be determined, it is possible that they are less reactive with the Neogen test. Additionally, the change in response may be due to the higher dilution with the modified protocol because the LPOD for the mussel homogenate at $0.22 \mathrm{mg} \mathrm{STX} \cdot 2 \mathrm{HCl} \mathrm{eq} / \mathrm{kg}$ was lower using the modified protocol compared with the standard protocol $(0.73$ versus 0.95 respectively; Table 3 ), and the LOD values calculated by linear interpolation were 0.682 and 0.316 , respectively.

\section{Conclusions}

This study highlights the challenge of the different ways of reporting total PST toxicity by different countries that use different TEFs. New TEFs were recommended by FAO/WHO in 2016, but may need to be updated after more recent TEFs based on oral toxicities were recently published (48). If adopted internationally, these TEFs will facilitate standard toxicity calculations and enable comparisons among countries. Furthermore, this will create a higher degree of accuracy and confidence for the international trade of shellfish.

The Neogen test showed good homogeneity across all 16 laboratories using both standard and modified protocols. The Neogen test may be acceptable for screening purposes in accordance with EC directives for oysters, especially using the standard protocol. The standard protocol showed a more conservative approach for oysters, with a probability of a negative response ( $\beta$-error) at the regulatory limit of less than 0.033 on $95 \%$ of occasions and an LOD of $0.710 \mathrm{mg} \mathrm{STX} \cdot 2 \mathrm{HCl} \mathrm{eq} / \mathrm{kg}$ and $0.734 \mathrm{mg}$ $\mathrm{STX} \cdot 2 \mathrm{HCl} \mathrm{eq} / \mathrm{kg}$ for the standard and modified protocols respectively, both of which were below the regulatory limit applied in most countries $(0.8 \mathrm{mg} \mathrm{STX} \cdot 2 \mathrm{HCl} \mathrm{eq} / \mathrm{kg})$. Using the standard protocol, $95 \%$ of laboratories were expected to have an LOD less than the regulatory level $(0.731 \mathrm{mg} \mathrm{STX} \cdot 2 \mathrm{HCl} \mathrm{eq} / \mathrm{kg})$. However, using the modified protocol for oysters, the LOD below which $95 \%$ of laboratories fell was $0.921 \mathrm{mg} \mathrm{STX} \cdot 2 \mathrm{HCl} \mathrm{eq} / \mathrm{kg}$. The test may not be acceptable for use with mussels in the European Union due to the high variability in the LPOD at the regulatory level of $0.8 \mathrm{mg} \mathrm{STX} \cdot 2 \mathrm{HCl} \mathrm{eq} / \mathrm{kg}$ and high variation in the LOD. For the toxin profiles used in the present study, the estimated LOD for mussels was 0.316 and 0.682 using standard and modified protocols, respectively. However, the LOD estimated with a $95 \%$ prediction interval was $1.1 \mathrm{mg}$ $\mathrm{STX} \cdot 2 \mathrm{HCl} \mathrm{eq} / \mathrm{kg}$ using both protocols, which is above the regulatory limit. The test may still be useful for mussels for nonregulatory purposes as part of a business risk mitigation program. The modified protocol with the conversion step could be further explored to be applied in shellfish samples that are highly contaminated with GTX1\&4. This study has proven the efficacy and applicability of the Neogen kit for oysters using the standard protocol. The authors recommend this rapid kit for use in industry testing, with parallel testing by PST-regulation laboratories for potential future official control.

\section{Acknowledgments}

We thank the TSQAP, Department of Primary Industry Water and Environment (Tasmania, Australia), for the provision of four of the naturally contaminated stock homogenates and Josh Poke
(Estuarine Oyster Company Pty Ltd) for providing the PST-free oysters free of charge. We also thank Neogen for the free-ofcharge provision of rapid test kits and readers for all laboratories. We acknowledge Stephen M. Conrad (FDA), Melody Paulus (CER Groupe, Belgium), and Bing C. Chai (National Measurement Institute, Australia) for their assistance in evaluating samples.

\section{References}

(1) Etheridge, S.M. (2010) Toxicon 56, 108-122. doi:10.1016/j. toxicon.2009.12.013

(2) Anderson, D.M., Cembella, A.D., \& Hallegraeff, G.M. (2012) Annu. Rev. Mar. Sci. 4, 143-176. doi:10.1146/annurev-marine120308-081121

(3) Knaack, J.S., Porter, K.A., Jacob, J.T., Sullivan, K., Forester, M., Wang, R.Y., Trainer, V.L., Morton, S., Eckert, G., McGahee, E., Thomas, J., McLaughlin, J., \& Johnson, R.C. (2016) Harmful Algae 57, 45-50. doi:10.1016/j.hal.2016.03.006

(4) CODEX (2008) Codex Alimentarius Commission, Joint Food and Agriculture Organization of the United Nations and World Health Organization Food Standards Program, Rome, Italy, STAN 292-2008

(5) The Philippines Bureau of Fisheries and Aquatic Resources (2014) http://www.bfar.da.gov.ph/LAW?fi=397 (accessed on April 3, 2017)

(6) Australia New Zealand Food Standards(2016) Australia New Zealand Food Standards Code-Schedule 19-Maximum Levels of Contaminants and Natural Toxicants, https://www. legislation.gov.au/Details/F2016C00197 (accessed on November 14, 2016)

(7) CODEX (2015) Codex Alimentarius Commission, Joint Food and Agriculture Organization of the United Nations and World Health Organization Food Standards Program, Rome, Italy, STAN 292-2008

(8) Official Methods of Analysis (2005) 20th Ed., AOAC INTERNATIONAL, Gaithersburg, MD, Method 2005.06

(9) Official Methods of Analysis (2011) 20th Ed., AOAC INTERNATIONAL, Gaithersburg, MD, Method 2011.02

(10) Official Methods of Analysis (2011) 20th Ed., AOAC INTERNATIONAL, Gaithersburg, MD, Method 2011.27

(11) Turner, A.D., McNabb, P.S., Harwood, D.T., Selwood, A.I., \& Boundy, M.J. (2015) J. AOAC Int. 98, 609-621. doi:10.5740/ jaoacint. 14-275

(12) U.S. Food and Drug Administration National Shellfish Sanitation Program - Guide for the Control of Molluscan Shellfish. Interstate Shellfish Sanitation Conference, http:// www.fda.gov/Food/GuidanceRegulation/ FederalStateFoodPrograms/ucm2006754.htm (accessed on October 24, 2015)

(13) Canadian Food Inspection Agency (2011) Government of Canada Implements New, Faster Testing Method for Shellfish Toxins, http://www.inspection.gc.ca/about-the-cfia/newsroom/ news-releases/shellfish-toxins/eng/1323652435046/ 1323652435047 (accessed on October 24, 2016)

(14) Costa, P.R., Baugh, K.A., \& Wright, B., RaLonde, R., Nance, S. L., Tatarenkova, N., Etheridge, S.M., \& Lefebvre, K.A. (2009) Toxicon 54, 313-320. doi:10.1016/j.toxicon.2009.04.023

(15) DeGrasse, S., Conrad, S., DiStefano, P., Vanegas, C., Wallace, D., Jensen, P., Hickey, J.M., Cenci, F., Pitt, J., Deardorff, D., Rubio, F., Easy, D., Donovan, M.A., Laycock, M., Rouse, D., \& Mullen, J. (2014) Deep Sea Res. Part II Top. Stud. Oceanogr. 103, 288-300. doi:10.1016/j.dsr2.2013.01.036

(16) Harrison, K., Johnson, S., \& Turner, A.D. (2016) Toxicon 119 , 352-361. doi:10.1016/j.toxicon.2016.06.019

(17) Dorantes-Aranda, J.J., Campbell, K., Bradbury, A., Elliott, C.T., Harwood, D.T., Murray, S.A., Ugalde, S.C., Wilson, K., 
Burgoyne, M., \& Hallegraeff, G.M. (2017) Toxicon 125, 110-119. doi: 10.1016/j.toxicon.2016.11.262

(18) Dubois, M., Demoulin, L., Charlier, C., Singh, G., Godefroy, S. B., Campbell, K., Elliott, C.T., \& Delahaut, P. (2010) Food Addit. Contam. Part A Chem. Anal. Control Expo. Risk Assess. 27, 859-868. doi:10.1080/19440041003662881

(19) Mcleod, C., Burrell, S., \& Holland, P. Review of the Currently Available Field Methods for Detection of Marine Biotoxins in Shellfish Flesh, https://www.food.gov.uk/science/research/ foodborneillness/shellfishresearch/fs102086 (accessed on April 7, 2017)

(20) Laycock, M.V., Jellett, J.F., Belland, E.R., Bishop, P.C., Thériault, B.L., Russell-Tattrie, A.L., Quilliam, M.A., Cembella, A.D., \& Richards, R.C. (2000) Harmful Algal Blooms, Proceedings of the Ninth International Conference on Harmful Algal Blooms, G.M., Hallegraeff S.I., Blackburn C.J., \& Bolch R.J. Lewis (Eds), Intergovernmental Oceanographic Commission of UNESCO, Hobart, Tasmania, pp 254-256

(21) Jellett, J.F., Roberts, R.L., Laycock, M.V., Quilliam, M.A., \& Barrett, R.E. (2002) Toxicon 40, 1407-1425. doi:10.1016/ S0041-0101(02)00153-8

(22) Turner, A.D., Stubbs, B., Coates, L., Dhanji-Rapkova, M., Hatfield, R.G., Lewis, A.M., Rowland-Pilgrim, S., O’Neil, A., Stubbs, P., Ross, S., Baker, C., \& Algoet, M. (2014) Harmful Algae 31, 87-99. doi:10.1016/j.hal.2013.10.014

(23) Turner, A.D., Tarnovius, S., Johnson, S., Higman, W.A., \& Algoet, M. (2015) Toxicon 100, 32-41. doi:10.1016/j. toxicon.2015.04.004

(24) Wong, C.-K., Hung, P., Ng, E.A.L., Lee, K.L.H., Wong, G.T.C., \& Kam, K.-M. (2010) Harmful Algae 9, 636-646. doi:10.1016/j. hal.2010.05.004

(25) Jawaid, W., Campbell, K., Melville, K., Holmes, S.J., Rice, J., \& Elliott, C.T. (2015) Anal. Chem. 87, 5324-5332. doi:10.1021/ acs.analchem. 5 b00608

(26) Turnbull, A.R., Tan, J.Y.C., Ugalde, S.C., Hallegraeff, G.M., Campbell, K., Harwood, D.T., \& Dorantest-Aranda, J.J. (2018) J. AOAC Int. 101, 480-489. doi:10.5740/jaoacint.17-0135

(27) AOAC International (2014) J. AOAC Int. 97, 1492-1495. doi:10.5740/jaoacint.BinaryGuidelines

(28) Random.org, Randomness and Integrity Services Ltd, http:// www.random.org (accessed on August 20, 2016)

(29) Food and Agriculture Organization/World Health Organization (2016) Technical Paper on Toxicity Equivalency Factors for Marine Biotoxins Associated with Bivalve Molluscs, FAO/ WHO, Rome, Italy

(30) European Food Safety Authority (2008) EFSA J. 6, 723. 10.2903/j.efsa.2009.1019
(31) Oshima, Y. (1995) J. AOAC Int. 78, 528-532

(32) Munday, R., Thomas, K., Gibbs, R., Murphy, C., \& Quilliam, M. A. (2013) Toxicon 76, 77-83. doi:10.1016/j.toxicon.2013. 09.013

(33) Quilliam, M.A. (2007) Supplemental Information for PSP Toxin CRMs: Structures, Molecular Weights, Concentrations and Toxicities, CRPM Technical Report CRM-PSP-20070411, National Research Council Canada, Halifax, Canada

(34) Wehling, P., LaBudde, R.A., Brunelle, S.L., \& Nelson, M.T. (2011) J. AOAC Int. 94, 335-347

(35) LaBudde, R.A., \& Harnly, J. (2012) J. AOAC Int. 95, 273-285. doi:10.5740/jaoacint.11-266

(36) Macarthur, R., \& von Holst, C. (2012) Anal. Methods 4, 2744. doi:10.1039/c2ay05719k

(37) Turner, A.D., Lewis, A.M., Rourke, W.A., \& Higman, W.A. (2014) J. AOAC Int. 97, 380-390. doi:10.5740/jaoacint.SGETurner

(38) Rey, V., Botana, A.M., \& Botana, L.M. (2017) Toxicon 129, 28-35. doi:10.1016/j.toxicon.2017.02.003

(39) Mok, J.S., Song, K.C., Lee, K.J., \& Kim, J.H. (2013) Fish. Aquat. Sci. 16, 137-142. 10.5657/FAS.2013.0137

(40) Kacem, I., Giménez Papiol, G., de la Iglesia, P., Diogène, J., Hajjem, B., \& Bouaïcha, N. (2015) Int. J. Food Prop. 18, 1075-1085. doi:10.1080/10942912.2014.913179

(41) Bricelj, V.M., \& Shumway, S.E. (1998) Rev. Fish. Sci. 6, 315-383. doi:10.1080/10641269891314294

(42) Turner, A.D., Lewis, A.M., Hatfield, R.G., Galloway, A.W., \& Higman, W.A. (2012) Toxicon 60, 1117-1134. doi:10.1016/j. toxicon.2012.07.013

(43) Bricelj, V.M., Cembella, A.D., \& Laby, D. (2014) Deep Sea Res. Part II Top. Stud. Oceanogr. 103, 308-317. doi:10.1016/j. dsr2.2013.05.014

(44) Smith, E.A., Grant, F., \& Ferguson, C.M.J. (2001) Appl. Environ. Microbiol. 67, 2345-2353. doi:10.1128/AEM.67.5.23452353.2001

(45) European Commission Regulation No. C(2002) 3044 (2002) Climate Change 2013 - The Physical Science Basis, Intergovernmental Panel on Climate Change (Ed), Cambridge University Press, Cambridge, United Kingdom, Vol. L221, pp 1-30

(46) Sakamoto, S., Sato, S., Ogata, T., \& Kodama, M. (2000) Fish. Sci. 66, 136-141. doi:10.1046/j.1444-2906.2000.00020.x

(47) Negri, A., Stirling, D., Quilliam, M., Blackburn, S., Bolch, C., Burton, I., Eaglesham, G., Thomas, K., Walter, J., \& Willis, R. (2003) Chem. Res. Toxicol. 16, 1029-1033. doi:10.1021/ tx $034037 \mathrm{j}$

(48) Selwood, A., Waugh, C., Harwood, D., Rhodes, L., Reeve, J., Sim, J., \& Munday, R. (2017) Toxins (Basel) 9, 73. doi:10.3390/ toxins 9020073 